\title{
A comparative study of the field emission properties of aligned carbon nanostructures films, from carbon nanotubes to diamond
}

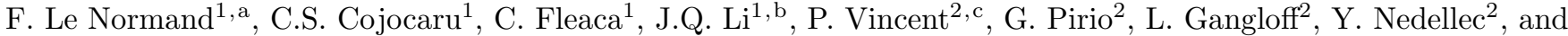 \\ P. Legagneux ${ }^{2}$ \\ 1 IPCMS/GSI, UMR 7504 CNRS, bât 69, 23 rue du Loess, P.O. Box 43, 67034 Strasbourg Cedex 2, France \\ 2 THALES R\&T, Départementale 128, 91747 Palaiseau Cedex, France
}

Received: 26 May 2006 / Accepted: 24 January 2007

Published online: 21 March 2007 - (c) EDP Sciences

\begin{abstract}
The electron field emission properties of different graphitic and diamond-like nanostructures films are compared. They are prepared in the same CVD chamber on $\mathrm{SiO}_{2} / \mathrm{Si}(100)$ and $\mathrm{Si}(100)$ flat surfaces, respectively. These nanostructures are thoroughly characterized by scanning electron emission (SEM), transmission electron microscopy (TEM), Raman spectroscopy, X-ray photoelectron spectroscopy (XPS) and Auger electron spectroscopy (AES). Films of dense aligned carbon nanotubes by far display the lowest threshold fields around few $\mathrm{V} / \mu \mathrm{m}$ and the largest emission currents. Carbon nanofibers, with platelet arrangement of the graphitic planes parallel to the substrate, exhibit higher emission thresholds around $10 \mathrm{~V} / \mu \mathrm{m}$. Diamond nanostructures, either modified through ammonia incorporation within the gas phase or not, exhibit the largest emission threshold around $25 \mathrm{~V} / \mu \mathrm{m}$. The high enhancement factors, deduced from the Fowler-Nordheim plots, can explain the low emission thresholds whereas limitations to the electron transport ever occur through different processes (i) surface modifications of the surface, as the transformation of the $\mathrm{SiO}_{2}$ barrier layer into $\mathrm{SiN}_{x}$ in the presence of ammonia evidenced by XPS; (ii) different orientation of the graphitic basal planes relative to the direction of electron transport (carbon nanofiber) and (iii) presence of a graphitic nest at the interface of the carbon nanostructure and the substrate, observed when catalyst is deposited through mild evaporation.
\end{abstract}

PACS. 81.05.Uw Carbon, diamond, graphite - 73.63.Fg Nanotubes $-79.70 .+q$ Field emission, ionization, evaporation, and desorption

\section{Introduction}

The vacuum electronic devices based on electron emission use mostly two main emission processes depending on the application: the thermoionic emission or "hot emission", and the field emission by tunnelling effect or "cold emission". Nowadays requirements are to develop powerful, high brightness and miniaturised electron sources for flat panels display, or microwave amplifiers, as well as parallel electron beam for microscopy and nanolithography. In this case, thermoionic sources find some limitations such as thermal compatibility and large distributions, both in electron energy and emission direction. By contrast the cold sources can be highly miniaturized and display nearly punctual sources with thinner energy distribution [1]. Moreover the emission is expected to be much stable with a longer lifetime. Among possible candidates,

\footnotetext{
${ }^{a}$ e-mail: Francois.Le-Normand@ipcms.u-strasbg.fr

b Present address: Lanzhou University, Department of Physics, P.R. China.

Present address: Laboratory of Physics of Materials and Nanostructures (LPMN), UMR CNRS, Villeurbanne Cedex, France.
}

the carbon nanotubes (CNTs) as well as other carbon sources such as doped CVD diamond, doped Diamond Like Carbon (DLC), amorphous carbon are presently intensively studied [1-9]. However the carbon nanotubes (CNTs) appear as the most promising emitters. They fulfill many advantages over other carbon sources. First, a high geometrical aspect ratio (diameter/length) with an emission radius that can be reduced to a size as low as 1-3 nm for a single-wall CNT (SWCNT) and in the 10$100 \mathrm{~nm}$ range for multi-wall CNT (MWCNT). This high aspect ratio allows switching on an electron emission with low extracting voltage. Second, the carbon is anyway an excellent electron emitter with a work function $\Phi$ around $5 \mathrm{eV}$. Third, CNTs exhibit both a strong hardness combined with a high flexibility, which is of great interest for the stability of the emitter. In addition a CNT without defects is expected to exhibit no dandling bonds, which infers an improved chemically stability and thus longer lifetimes compared to conventional field emission tips like Spindt tips. Recent results on CNTs show that excellent current stability for hours can be obtained $[3,4]$. Fourth, graphitic shells that make up the walls of the CNTs are excellent electrical conductors. Finally, the deposition of films and arrays of aligned CNTs is at the present time controlled on 
pretreated samples either by thermal or plasma-assisted CVD methods with an optimized and controlled density $[10,11]$. Thus high electron densities were reported in the literature, up to $1 \mathrm{~A} / \mathrm{cm}^{2}[12]$. On the other hand electron emission from diamond nanostructures at low threshold voltage has been found. The process however is controversial. A low electron affinity for diamond [13], conduction at the diamond film-substrate interface [14], emission from states at the Fermi level by either graphite agglomerates or surfaces states or defects in the diamond film [15] have been invoked. Hence the field emission properties of diamond films are strongly dependent on the doping, either by boron or nitrogen. However these results are not always reliable due to different experimental measurement of the electron emission (either in a spherical or planar configuration) and they often suffer from some lack of characterization of the carbon nanostructures. Therefore a rationale is someway required between the field emission properties, on one part, and chemical, structural and morphological properties of the carbon nanostructures on another part.

We present here a comparative study of the field emission properties of vertically aligned films of different graphitic nanostructures and nitrogen-doped diamond films prepared in the same reactor by Direct Current Hot Filament Catalytic CVD (DC HF CCVD). This CVD process allows the growth of CNTs and many other aligned fiber nanostructures as well as diamond films $[16,17]$. This set up combines an activation of the gas mixture both by a DC gas discharge to produce ions, and by hot filaments to produce radicals, and specific high vacuum surface preparations of the substrate (thermal treatments, deposition of catalyst, ...). Thorough characterizations of the nanostructures formed include in this study surface analyses by in-situ electron spectroscopies (X-ray electron spectroscopy and Auger electron spectroscopy), Raman spectroscopy, MEB and TEM. This comparative study on widely different carbon nanostructures shows that (i) the threshold electron emission is largely dependent on the nature of the carbon nanostructures and (ii) the CNTs display better field emission characteristics both for turn-on field and current density but (iii) saturation of the electron emission is ever observed.

\section{Experimental}

\subsection{Sample preparation}

\subsubsection{Diamond nanostructures}

The substrate for diamond depositions were prepared from Si(100) substrate (thickness $265 \mu \mathrm{m}$, size $8 \times 8 \mathrm{~mm}^{2} ; \mathrm{Sb}$ $n$-doped with $\rho=17 \mathrm{~m} \Omega . c m)$. They were treated subsequently in a ultrasonic bath with acetone $(5 \mathrm{~min})$, ethanol (5 min), an aqueous diamond powder $(1 \mu \mathrm{m})$ suspension at $343 \mathrm{~K}$ for 3 hours to increase the nucleation density, rinsed with deionized water $(2 \mathrm{~min})$ and finally ethanol once again $(2 \mathrm{~min})$.

\subsubsection{Graphite-type nanostructures}

Carbon nanostructures were prepared in three subsequent steps.

A $\mathrm{SiO}_{2}$ layer of depth $e(2<e<8 \mathrm{~nm})$ was first deposited by a DECR process on a $\mathrm{Si}(100)$ sample ( $\mathrm{Sb}$ $n$-doped with $\rho=3 \mathrm{~m} \Omega$.cm). The role of this $\mathrm{SiO}_{2}$ layer was twofold: (i) to prevent the metal and silicon interdiffusion leading to silicide formation and catalyst deactivation and (ii) to minimize the wetting interactions between the transition metal and the substrate and thus to get an easier fragmentation into divided particles.

Transition metal (TM) film was deposited on these $\mathrm{SiO}_{2} / \mathrm{Si}(100)$ substrates by sputtering of either a Fe or Co target (grade $99.95 \%$ for both targets) at room temperature using either a magnetron $\mathrm{DC}(\mathrm{Co})$ or a $\mathrm{RF}(\mathrm{Fe})$ source (Ar ${ }^{+}$pressure: $4 \times 10^{-3} \mathrm{mbar}$, and gas flow: $15 \mathrm{~cm}^{3} / \mathrm{min}$ ). The power energy was $110 \mathrm{~W}$ (DC source) and the ion current was $110 \mathrm{~mA}$ (RF source), respectively. The residual vacuum limit was around $10^{-7}$ mbar. Within these conditions the calibrated deposition rates were in the range 0.05-0.10 nm/min, depending on the transition metal. One of the samples (Co5) was in situ prepared by evaporation in ultra high vacuum (UHV) at around $10^{-10} \mathrm{mbar}$ and $1083 \mathrm{~K}$ [18].

\subsection{Carbon nanostructures growth}

The growth of carbon nanostructures was carried out in the same experimental set up that has been previously described, whatever the diamond or graphite nature of carbon is $[16,17]$.

\subsubsection{Diamond deposition}

The conditions for diamond deposition are summarized in Table 1. Briefly the deposition occurs in two steps by HF CVD (nucleation for $30 \mathrm{~min}$ at $973 \mathrm{~K}$ and $2 \% \mathrm{CH}_{4}$, and growth for 10 hours at $1073 \mathrm{~K}$ and $1 \% \mathrm{CH}_{4}$ ) with variable ammonia concentrations in the gas phase ranging from 0 to $10500 \mathrm{ppm}$.

\subsubsection{Graphitic carbon deposition}

Carbon was deposited in a UHV chamber (limiting vacuum $10^{-9}$ torr) by a Direct Current-enhanced and Hot Filaments-enhanced Catalytic CVD (DC HF CCVD) process that had been previously described [17]. In this process the reactive gas mixture $\left(\mathrm{C}_{2} \mathrm{H}_{2}: \mathrm{H}_{2}: \mathrm{NH}_{3}\right)$ was activated both by hot filaments to produce neutral radical species, and by a DC gas discharge created by polarisation between two electrodes settled a few centimeters away from the sample to produce activated and ionic gas species. The sample was negatively biased relative to the cathode in the range $25-40 \mathrm{~V}$. This allowed extracting a constant ionic beam that impinged the surface of the sample. The literature provides some other references 
Table 1. Conditions of nanodiamond films preparation and field emission properties. Nucleation : $T=973 \mathrm{~K} ; P=23.5 \mathrm{mbars}$; $\left[\mathrm{CH}_{4}\right]=2 \% ; t=0.5 \mathrm{~h}$. Growth: $T=1073 \mathrm{~K} ; P=30 \mathrm{mbars} ;\left[\mathrm{CH}_{4}\right]=1 \% ; t=10 \mathrm{~h}$. Otherwise throughout the deposition process, filaments power $=185 \mathrm{~W}$; filaments distance $=5 \mathrm{~mm}$ and gas flow $=200 \mathrm{sccm}$.

\begin{tabular}{|c|c|c|c|c|c|c|c|}
\hline Sample & $\% \mathrm{NH}_{3}(\mathrm{ppm})$ & Morphology & $\begin{array}{c}\text { Initial } \\
\text { threshold } \\
(\mathrm{V} / \mu \mathrm{m})\end{array}$ & $\begin{array}{c}\text { Long term } \\
\text { threshold } \\
(\mathrm{V} / \mu \mathrm{m})\end{array}$ & $\begin{array}{c}\text { Emission density } \\
\left(\mu \mathrm{A} / \mathrm{cm}^{2}\right)(\text { for the field } \\
E(\mathrm{~V} / \mu \mathrm{m}))\end{array}$ & $\beta$ & Stability \\
\hline ND 0 & 0 & Film & 25 & 25 & $20(40)$ & 350 & Stable \\
\hline ND 45 & 45 & Film & $>25$ & - & - & & - \\
\hline ND 500 & 500 & Film & $>25$ & - & - & & - \\
\hline ND 2000 & 2000 & Film & 14 & - & - & & Unstable \\
\hline ND 4000 & 4000 & Film & 15 & 25 & $20(22)$ & & Unstable \\
\hline ND 6000 & 6000 & Film & 5 & $>10$ & $10(7)$ & 500 & Unstable \\
\hline ND 10500 & 10500 & Particles & 7 & - & $15(9)$ & & Unstable \\
\hline
\end{tabular}

Table 2. Some important parameters of the nanostructures grown and field emission properties. Other growth conditions are: overall flux: $100 \mathrm{sccm} ; P=15$ mbar; $t=15 \mathrm{~min}$; Filaments power $=150 \mathrm{~W}$ corresponding to a temperature of around $2223 \mathrm{~K}$; distance between the cathode of the plasma and the substrate $=5 \mathrm{~mm}$; plasma activation potential within 300 and $400 \mathrm{~V}$.

\begin{tabular}{|c|c|c|c|c|c|c|c|c|c|c|c|c|}
\hline$\overline{\text { Sample }}$ & & Preparation & & & & & & Growth & & & $\begin{array}{c}\text { Emission } \\
\text { parameters }\end{array}$ & \\
\hline & $\begin{array}{l}\mathrm{SiO}_{2} \\
\text { layer } \\
(\mathrm{nm})\end{array}$ & $\begin{array}{l}\text { Transition } \\
\text { metal }\end{array}$ & $\begin{array}{c}\text { Mode } \\
\text { metal } \\
\text { deposition }\end{array}$ & $\begin{array}{l}\mathrm{TM} \\
\text { layer } \\
\text { hickness } \\
(\mathrm{nm})\end{array}$ & $\begin{array}{c}T_{G} \\
\mathrm{~K}\end{array}$ & $\begin{array}{c}\mathrm{C}_{2} \mathrm{H}_{2}: \mathrm{NH}_{3}: \mathrm{H} \\
(\%) \\
P=I_{e} \times V_{e} \\
(\mathrm{~mW})\end{array}$ & $\begin{array}{l}\text { Extraction } \\
\text { power } P\end{array}$ & $\begin{array}{c}\text { Density }\left(10^{10} \mathrm{~cm}^{-2}\right) \\
\text { and nature }(* *) \\
\text { of the carbon } \\
\text { structures }\end{array}$ & $\begin{array}{l}\text { Mean } \\
\text { size } \\
(\mathrm{nm})\end{array}$ & $\begin{array}{c}\text { Emission } \\
\text { threshold } \\
(\mathrm{V} / \mu \mathrm{m})\end{array}$ & $\begin{array}{c}\text { Emission } \\
\text { density } \\
\left(\mu \mathrm{A} / \mathrm{cm}^{2}\right) \\
\text { for the field } E \\
{[\mathrm{~V} / \mu \mathrm{m}]}\end{array}$ & $\beta$ \\
\hline $\mathrm{Fe} 1$ & 4.3 & $\mathrm{Fe}$ & $\operatorname{MS}(*)$ & 4.8 & 973 & 20:0:80 & 240 & $\begin{array}{l}\text { (Tangled and } \\
\text { Heterogeneous } \\
\text { CNTs + a-c }\end{array}$ & $10-15$ & $\begin{array}{c}1.5 \\
{[4.15]}\end{array}$ & 55 & 1770 \\
\hline $\mathrm{Fe} 2$ & $"$ & $\mathrm{Fe}$ & $\operatorname{MS}(*)$ & 4.8 & $"$ & $20: 16: 64$ & 150 & $\begin{array}{c}5 \\
\text { (Aligned CNTs) }\end{array}$ & $10-20$ & 2 & 265 & 1690 \\
\hline Co1 & 8.0 & Co & $\operatorname{MS}(*)$ & 2.5 & 973 & $20: 3: 77$ & 30 & $\stackrel{>1}{>1}$ & $15-25$ & 3 & 105 & 1300 \\
\hline $\mathrm{Co} 2$ & 8.0 & Co & $\operatorname{MS}(*)$ & 2.5 & 1173 & 20:3:77 & 30 & $\begin{array}{c}>1 \\
\text { (Aligned CNTs) }\end{array}$ & $20-30$ & 1.9 & 85 & 1540 \\
\hline Co3 & 4.3 & Co & $\operatorname{MS}(*)$ & 1.7 & 973 & $20: 16: 64$ & 30 & $\begin{array}{c}10 \\
\text { (Aligned SiNC) }\end{array}$ & $\begin{array}{l}25 \text { (base) } \\
10 \text { (tip) }\end{array}$ & 14.5 & $\begin{array}{l}0.5 \\
{[43]}\end{array}$ & 215 \\
\hline $\mathrm{Co} 4$ & 8.0 & Co & $\operatorname{MS}(*)$ & 2.5 & 973 & 20:0:80 & 30 & $\begin{array}{c}5 \\
\text { (Aligned CF) }\end{array}$ & $\begin{array}{l}30 \text { (base) } \\
15 \text { (tip) }\end{array}$ & 8.2 & $\begin{array}{l}4.8 \\
{[17]}\end{array}$ & 280 \\
\hline Co5 & 8.0 & Co & $\mathrm{VE}(*)$ & 3.0 & 973 & $20: 0: 80$ & 20 & $\begin{array}{c}\text { (Aligned CNTs) } \\
2.2\end{array}$ & 20 & 2 & $\begin{array}{c}15 \\
{[3.6]}\end{array}$ & 1780 \\
\hline
\end{tabular}

* MS: Magnetron sputtering; VE: vacuum evaporation. ${ }^{* *}$ aC: amorphous carbon; CNTs: carbon nanotubes; SiNC: oxynitride of silicon; CF: carbon fibers.

of similar set up for carbon film growth [19-32]. It was shown elsewhere that the nature and the morphology of the nanostructures either grown or redeposited after sputtering and etching was strongly affected by the ammonia concentration in the gas mixture, by the nature, the thickness and the mode of deposition of the TM (either Fe or Co) [33]. Table 2 summarizes these parameters used for the preparation of these nanostructures.

\subsection{Characterization of the nanostructures}

In situ chemical surface analyses were carried out by XPS and AES, in a chamber directly connected to the experimental UHV chamber. Details on surfaces analyses by electron spectroscopies were reported elsewhere [34]. Raman spectra were recorded with a Renishaw spectrometer using a He-Ne laser at $\lambda=632.8 \mathrm{~nm}$ equipped with a Notch filter and working in a backscattering geometry.

The samples were furthermore observed by SEM for the general morphology of the deposition and by TEM and HRTEM for structural characterization of the nanostructures. SEM was performed on a XL30S-FEG PHILIPPS working at $3 \mathrm{kV}$ and TEM was performed on a TOPCON 002B microscope operating at $200 \mathrm{kV}$. Carbon nanostructures were scratched by a diamond tip from the sample and directly pulled on a copper grid covered with amorphous carbon membrane and drilled with holes for accurate observations. 


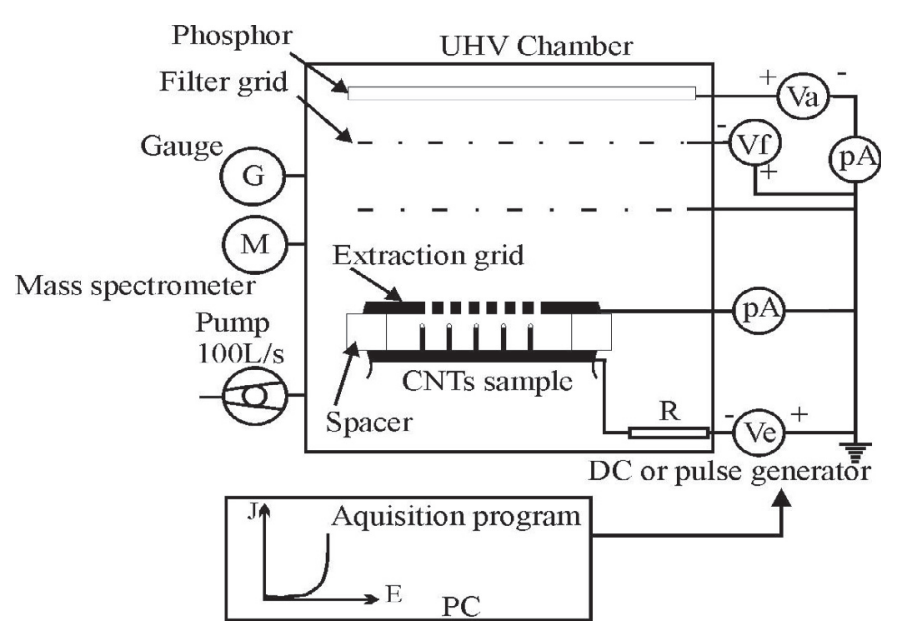

Fig. 1. Experimental set up for field emission measurements (triode configuration).

\subsection{Field emission measurements}

The field emission measurements were performed at THALES-R\&T (Domaine de Corbeville-Orsay, France) on an UHV set up (limiting vacuum $10^{-9}$ torr) which is displayed in Figure 1. A planar triode configuration was used, in which the sample was fixed in front of an extraction grid biased to the potential $V$ and distant by $d=110 \mu \mathrm{m}$ by mean of a quartz spacer. The mean apparent electric field around the sample was then $E=V / d$. The emitted electrons were collected on an ITO (indium tin oxide)/phosphorus flat anode screen integrating filtration grids to discriminate the secondary electrons. The emitted current $I_{a}$ was measured with a picoamperometer. The current density $j=I_{a} / S$ was calculated from an emitting surface $S$ estimated to $0.7 \mathrm{~mm}^{2}$, accounting for the opaqueness of the extraction grid [35].

The samples were conditioned by progressively rising the extraction potential before performing a full cycle. This one was carried out by subsequently rising and dropping the extraction potential. Thus many cycles were performed on the same sample up to a saturation of the electron emission. Stable conditions were obtained after many of these cycles and we report only the results of the steady field emission properties of the sample. The emission centers were visualized on the screen and it was checked that the emission properties occurred from more than one single emission center. The threshold emission was arbitrarily defined as the field from which an emission can be detected, which presently meant an emission density above $0.1 \mathrm{nA} / \mathrm{cm}^{2}$. The turn-on field was arbitrarily fixed as the field with an emission of $0.1 \mu \mathrm{A} / \mathrm{cm}^{2}$. Let us remind that the reported values, when compared with data of the literature, have only a relative signification as they strongly depend on the experimental set-up.

The field emission intensity as a function of the applied field is mostly described in the literature within the Fowler-Nordheim (FN) theory [36]. It involves the following assumptions:

- A triangular barrier, neglecting the space charge effect.
- The emission was calculated from the FowlerNordheim (FN) theory, strictly valuable for a flat and metallic emission center. The tip effect, in the case of either CNTs or any other strongly anisotropic material with a high aspect ratio, was accounted by a geometric enhancement factor $\beta$ that measures the ratio of the local field at the tip to the mean apparent field $E$. In the case of a pure whisker this shape factor can be approximated to the aspect ratio of the emitter, that means $\beta \approx h / d$ where $h$ and $d$ are the height and the diameter of the whisker and $h \gg d$, respectively [37].

- Temperature effects were neglected.

Therefore within the FN framework the current density $j$ can be expressed as

$$
j=\frac{I_{a}}{S}=A \beta^{2} \frac{E^{2}}{\Phi} \exp \left(-\frac{B \Phi^{3 / 2}}{\beta E}\right)
$$

with constants $A=1.54 \times 10^{-6}$ and $B=6.49 \times 10^{9}$ for $E$ in V.m ${ }^{-1}$ and $\Phi$ in $\mathrm{eV} . \Phi$ was fixed to $5.0 \mathrm{eV}$, the value generally accepted for graphite. Within these assumptions and according to equation (1), a $\operatorname{Ln}\left(I / E^{2}\right)=f(1 / E)$ plot allowed determining $\beta$ from the slope of the FN plot.

\section{Results}

\subsection{Field emission from carbon nanotubes grown with iron catalyst displaying different orientations of the graphitic shells}

Figure 2A, B displays SEM images of samples Fe1 and $\mathrm{Fe} 2$, respectively. The difference stems from a high concentration of ammoniac (16\%) in the gas mixture in the last case. Within the extraction plasma, an extraction power $P$ is defined as the product of the extraction voltage $V_{e}$ times the intensity of the electrical current on the sample $I_{e}$ : this extraction power is indeed dependent on the nature of the gas and the ammonia content is among the most important parameter to control in order to grow either aligned or tangled CNTs. The former sample displays completely tangled nanostructures with an heterogeneous size distribution of iron particles. Biggest particles around $100 \mathrm{~nm}$ and some smaller ones are encapsulated with graphitic carbon shells (Fig. 3B) whereas the smallest ones $(10-15 \mathrm{~nm})$ are hold at one end of a CNT which displays an appreciable length $(\gg 1 \mu \mathrm{m})$ and few walls (around 4-7) (Fig. 3A). Most of them show a "bamboo" shape. By contrast sample Fe2 exhibits a very good alignment of CNTs in the direction normal to the substrate (Fig. 2B). They exhibit an uniform diameter distribution around 15-20 nm with few walls (around 4-5) (Fig. 3C). This dramatic enhancement in the alignment of the CNTs in the presence of ammoniac can be explained by a promoted sputtering yield by the heavier ammoniaderived ions of the gas phase. These ammonia-derived species maintain clean and free the catalytic iron surface for hydrocarbon adsorption and further CNTs growth [33]. In addition they also probably play a role in a more homogeneous fragmentation of the iron film into particles. The 
A

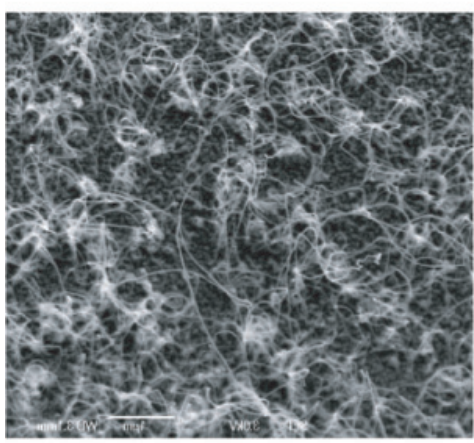

D

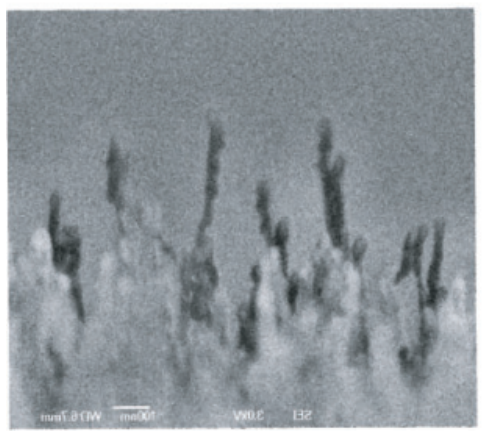

G

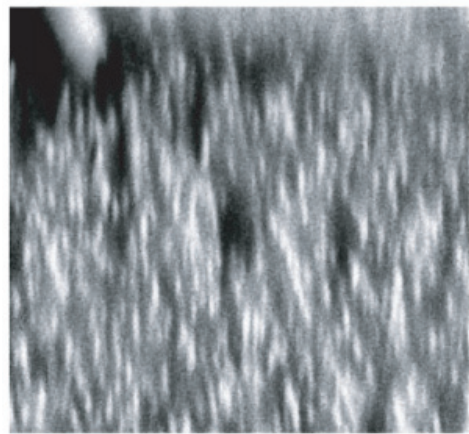

B

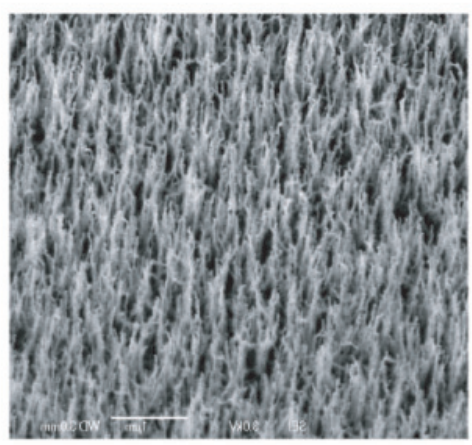

E

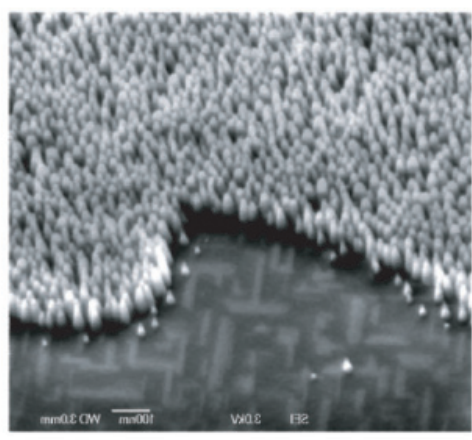

$\mathrm{H}$

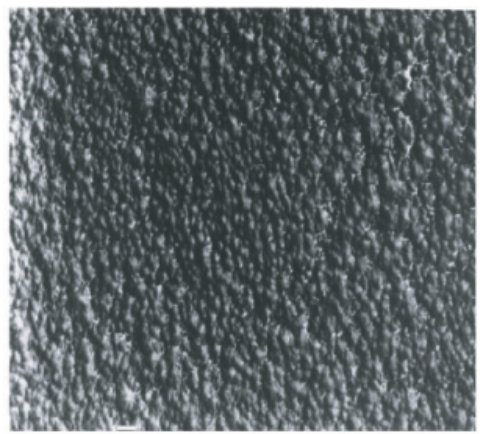

C

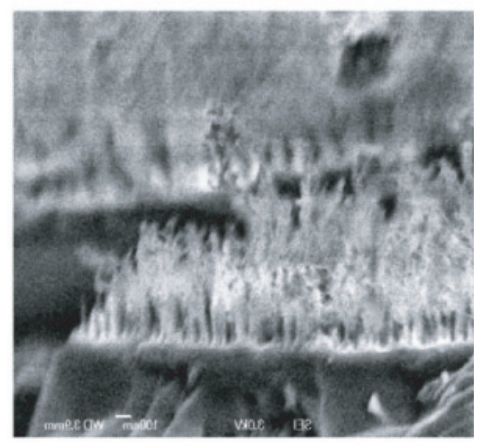

$\mathrm{F}$

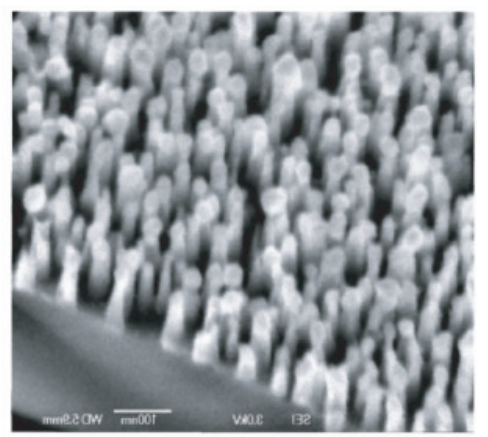

I

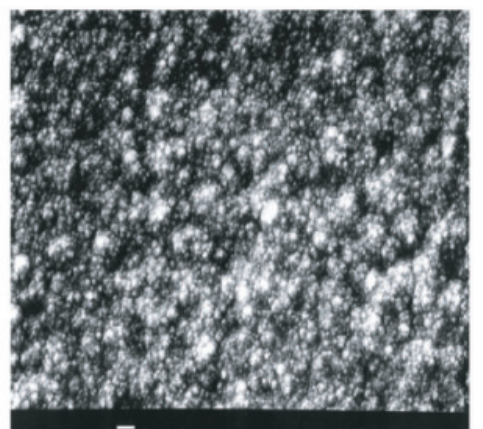

Fig. 2. SEM images of (A) sample Fe1; (B) sample Fe2; (C) sample Co1; (D) sample Co2; (E) sample Co3; (F) sample Co4; (G) sample Co5; (H) sample ND0 and (I) sample ND6000. The samples are imaged at variable incidence angles of the electron beam.

carbon nature of the deposit and the surface modifications of the sample are investigated by AES and XPS. Two important pieces of information can be drawn up from the comparison of the XPS spectra on samples Fe1 and Fe2 illustrated in Figure 4 at different steps of the process: (1) just after Fe deposition at room temperature by magnetron sputtering; (2) after subsequent reduction at $973 \mathrm{~K}$ with the gaseous mixture reported in Table 2 and finally (3) after CNTs growth. First, as exhibited by the wide XPS spectra (Fig. 4-IA, IB), the C1s contribution is surprisingly low on sample $\mathrm{Fe} 2$ after CNTs growth whereas this is the only one contribution on sample Fe1, inferring that carbon fully and thickly covers the substrate on Fe1 sample. This is in good agreement with the morphologies of the carbon films depicted in Figure 2A, B. The C1s (not shown) contribution displays one broad feature at $284.8 \pm 0.2 \mathrm{eV}$, but the sensitivity of the $\mathrm{C} 1 s$ core level and the limited XPS resolution prevent to get further information on the nature of carbon: diamond-like, graphitic or amorphous carbon. Combined use of AES and ELS is more useful to investigate the true nature of carbon (Fig. 5). On sample Fe1 the AES C KVV transition exhibits a featureless shape, characteristic of a highly amorphous carbon nature [34]. Moreover an intense N1s contribution at $397.1 \mathrm{eV}$ is detected on sample Fe2, suggesting an extensive silicon nitride formation (Fig. 4-IB and Fig. 4IVB). This is confirmed by the shift and the uniqueness of the $\mathrm{Si} 2 p$ core level to $101.1 \mathrm{eV}$ after CNTs growth [38] whereas the $\mathrm{SiO}_{2}$ and the $\mathrm{Si}$ contributions at $103 \mathrm{eV}$ and $99.3 \mathrm{eV}$, respectively, disappear (Fig. 4-IIIB). This 


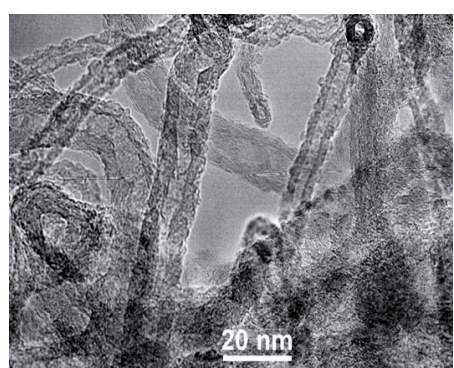

D

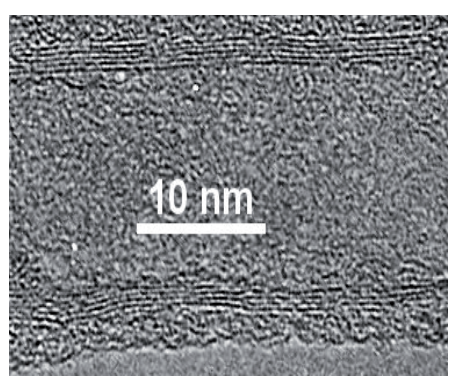

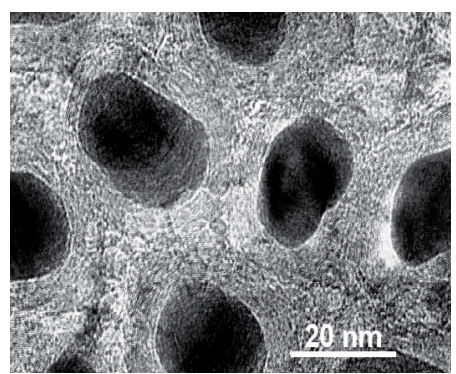

E

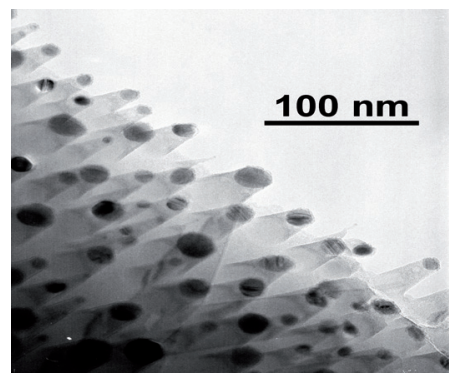

$\mathrm{C}$

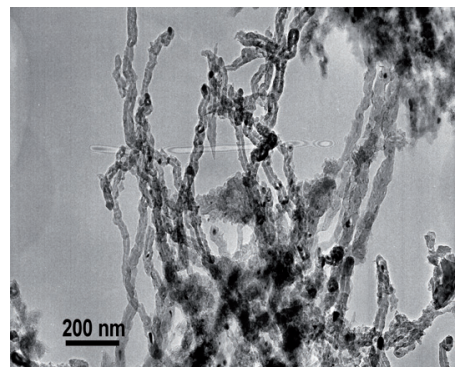

F

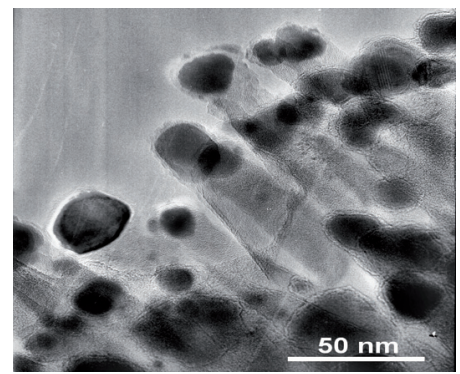

G

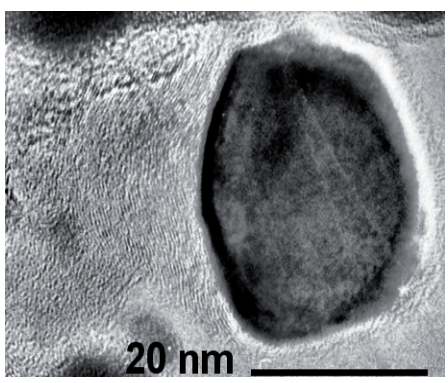

$\mathrm{H}$

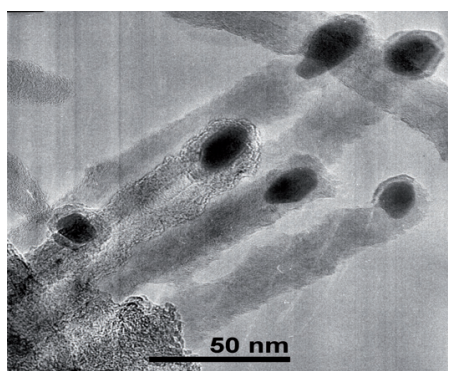

Fig. 3. TEM images on (A) sample Fe1 showing CNTs; (B) sample Fe1 showing particles encapsulated by graphitic carbon. Amorphous carbon can also be seen; (C) sample Fe2; (D) high magnitude image of sample Fe2 showing a CNT. On the high magnitude image the graphitic base planes are visible with an interplanar distance of $0.34 \mathrm{~nm}$; (E) sample Co3; (F) sample Co4; $(\mathrm{G})$ high magnitude image of the sample Co4 showing the stacking of the graphitic base plans and (H) sample Co5.

behavior has been observed whatever the sample is once both ammonia is added to the gas mixture and a biasactivated process is used for CNTs growth. In addition an iron reduction step is required, carried out at $973 \mathrm{~K}$ preliminary to the CNTs growth, in order to obtain metallic iron particles $\left(\mathrm{Fe}^{0}\right)$ which yields a $\mathrm{Fe}_{2 \mathrm{p} 3 / 2}$ single contribution at $707 \mathrm{eV}$ instead of $711 \mathrm{eV}$ ( $\mathrm{Fe}^{\mathrm{III}}$ from oxide with an $\mathrm{O} 1 s$ contribution at $530 \mathrm{eV}$ ) before reduction (Figs. 4IIA, IIB). This point has been checked systematically as the CNTs growth is strongly perturbed if iron particles are not preliminary reduced.

The field emission behavior of these Fe@CNTs nanostructures is shown in Figure 6 for some representative stabilized cycles. The electron emission exhibits in both cases an emission threshold lower than or equal to $2 \mathrm{~V} / \mu \mathrm{m}$ with very large and close geometric enhancement factors $\beta$, estimated from the linear FN plots to $\sim 1700$ for both samples (Fig. 7). These values are in good agree- ment with the values reported in the literature for such CNTs configurations [1]. The ratio of tube lengths (in the order of few micrometers for the longest) to mean diameters (around 15-20 nm), exceeds two orders of magnitude. This means that the assumption of the nanotubes to whiskers is only a rough assumption. The slight difference observed in the threshold emission in favor of tangled nanotubes in sample Fe1 could be explained by the weaker perturbation of the Fe@CNT emitter by other ones in the vicinity on sample Fe1, while on sample Fe2 most of the CNTs with rather equivalent lengths are oriented in the same direction and the screening of the field is larger. However saturation of the emission is rapidly reached at higher field and a break to the FN plot is always observed, especially on sample Fe1. The maximum in emission density is quoted to $60 \mu \mathrm{A} / \mathrm{cm}^{2}$ at $4.2 \mathrm{~V} / \mu \mathrm{m}$ for the sample $\mathrm{Fe} 1$ with disoriented CNTs, but $360 \mu \mathrm{A} / \mathrm{cm}^{2}$ at $4.8 \mathrm{~V} / \mu \mathrm{m}$ for the sample Fe2 with aligned CNTs. The origin of this 
IA

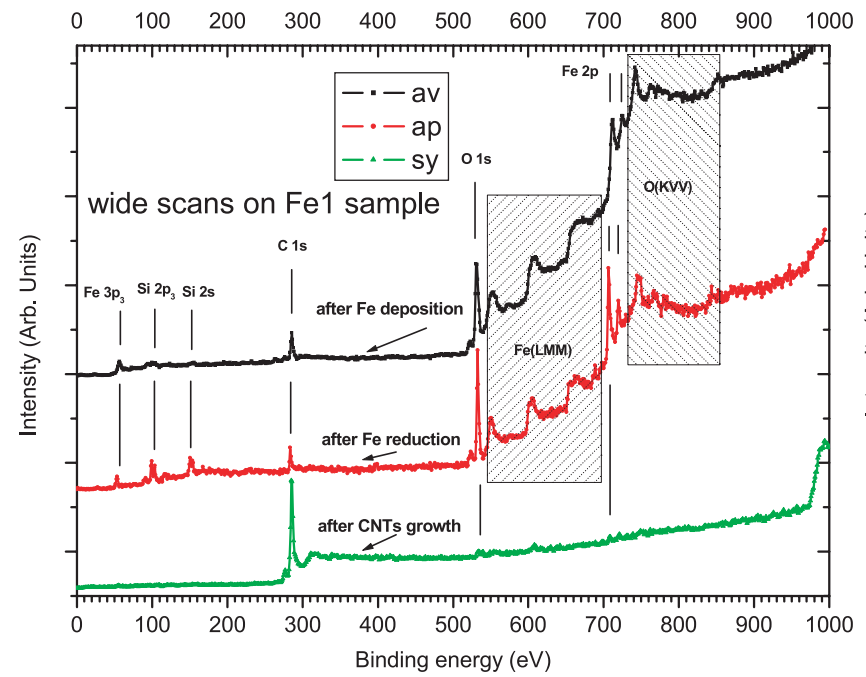

IB

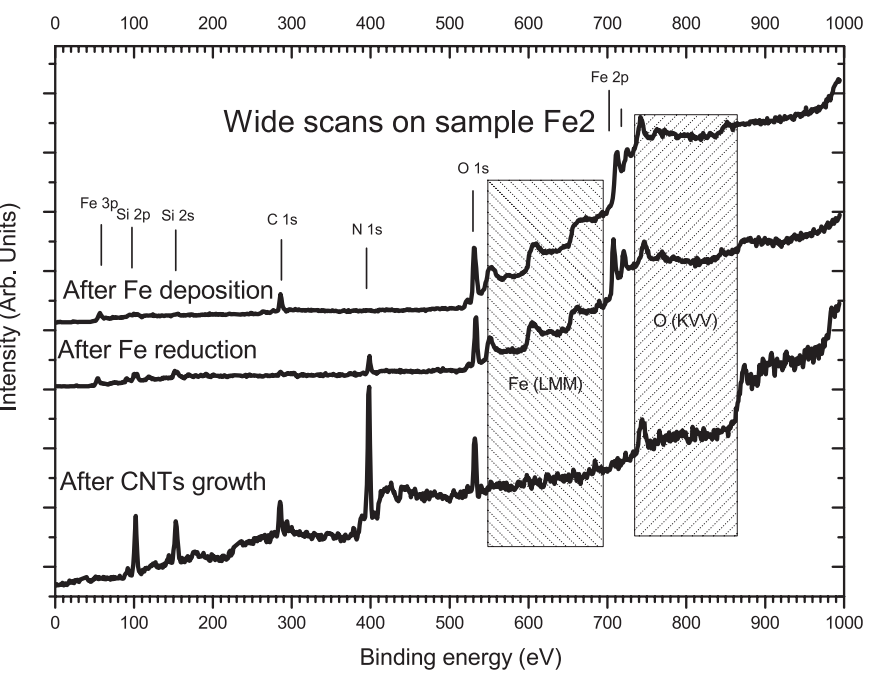

IIB
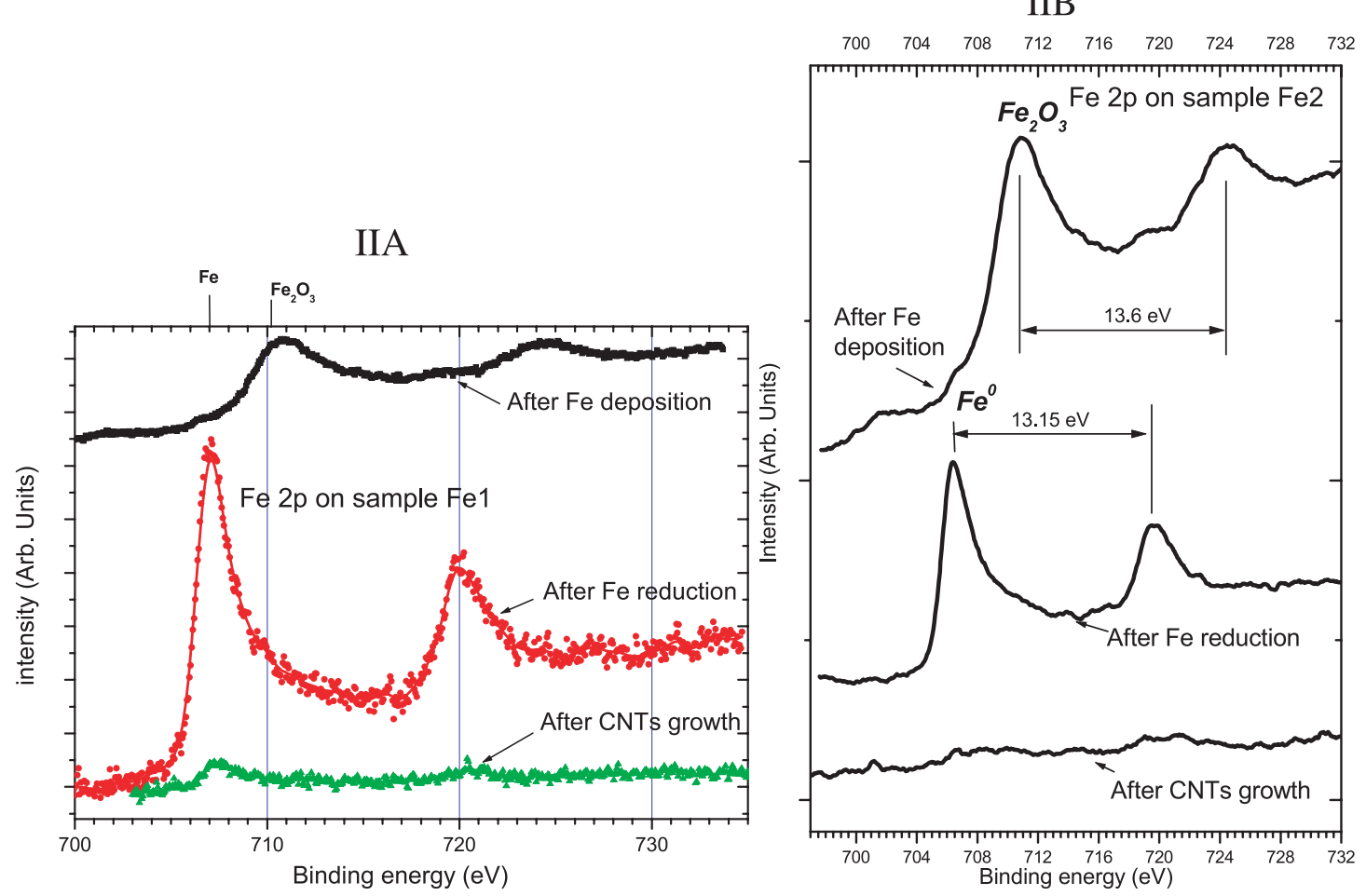

Fig. 4. XPS spectra on samples (A) Fe1; (B) Fe2. Panel displays (I) wide scans; (II) Fe2p; (III) (next) Si2p and (IV) (next) $\mathrm{O} 1 s$ (sample $\mathrm{Fe} 1$ ) and $\mathrm{N} 1 s$ (sample Fe2) core levels, respectively.

saturation is not quite clear, but at high field, heating of the sample occurs resulting in some desorption of adsorbed species and even breaking or burnt off of the nanotube. As it is expected that the longest CNTs are the first emitter center, it is likely that either desorption of adsorbed species or irreversible consumption of a nanotube leads to the substitution by a new emission center in the vicinity of the emission center. However it is unlikely to find again a new emitter site in the vicinity on sample Fe1, whereas on sample $\mathrm{Fe} 2$ the high density of aligned tubes infers that a new center in the vicinity of the burnt off emitter will easily substitute to it. Moreover on sample Fe1 the carbon nanotubes initially tangled on the substrate surface, has to align along the direction of the electric field in order to be a potential emitter. This has been indeed shown for an electric field far lower than $1 \mathrm{~V} / \mu \mathrm{m}[39,40]$, but it results from this initial morphology that the density of potential electron emitters is much lower on sample Fe1. Saturation to the emission may also occur through limitations in the electron transport. This point is further discussed. In 

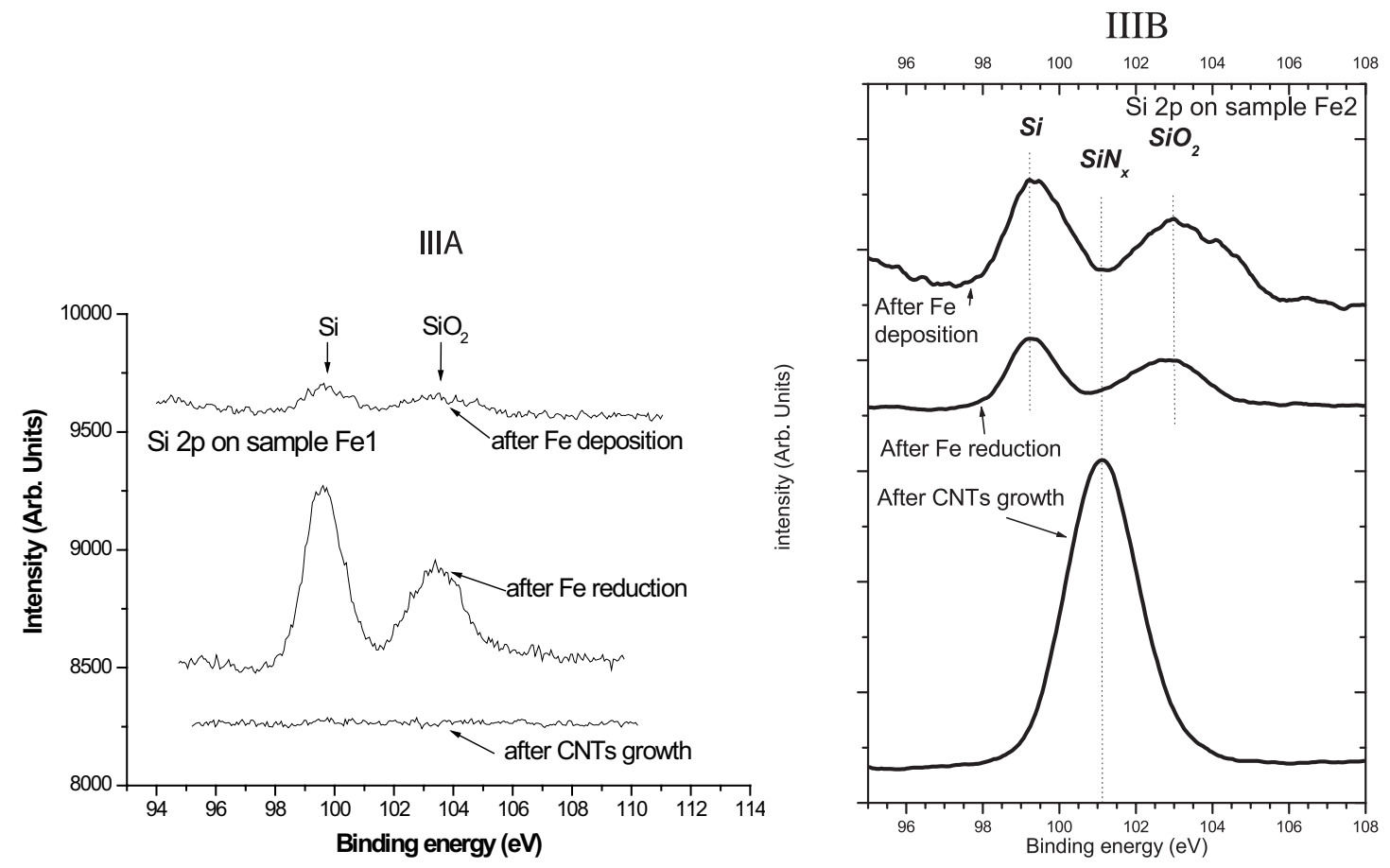

Fig. 4. Continued.

conclusion, the aligned or tangled character of the Fe@CNTs has a weak effect on the field emission threshold but a strong one on the saturation density.

\subsection{Field emission from carbon nanotubes grown with cobalt catalyst at different temperatures}

The elaboration process and the characteristics of electron emission from samples Co1 and Co2 are displayed in Table 2. The two films were grown at different temperatures, $973 \mathrm{~K}$ and $1173 \mathrm{~K}$, respectively. In both cases multiwalled carbon nanotubes with a cobalt particle on top of them $(\mathrm{Co} @ \mathrm{CNT})$ are grown and are aligned in the direction normal to the substrate (Figs. 2C and D). Small CNTs (around $300 \mathrm{~nm}$ ) are obtained on the sample Co1 grown at lower temperature but both samples exhibit heterogeneous length distributions. The XPS spectra (not shown) confirm the silicon nitride formation at the surface of the substrate. The graphitic nature of the deposit is also evidenced by Raman spectroscopy (Fig. 8). Many defects are present on both samples as exhibited by an intense D Raman band at $1332 \mathrm{~cm}^{-1}$ compared to the $\mathrm{G}$ band at $1585 \mathrm{~cm}^{-1}$. This $\mathrm{G}$ band clearly exhibits a shoulder at $1620 \mathrm{~cm}^{-1}$ which is much better resolved for sample Co2. The $\mathrm{G}$ band is weak and broad on sample Co1, inferring that the carbon nanotubes are much more defective on this sample.

The two samples start to emit at an emission threshold around $3 \mathrm{~V} / \mu \mathrm{m}$ (sample Co1) and $2 \mathrm{~V} / \mu \mathrm{m}$ (sample Co2) with high enhancement factors $\beta$ around 1300 (Figs. 6, 7). However both samples rapidly reach a saturation of the electron emission at higher fields. The maximum of elec- tron emission densities are $105 \mu \mathrm{A} / \mathrm{cm}^{2}$ at $10.4 \mathrm{~V} / \mu \mathrm{m}$ and $85 \mu \mathrm{A} / \mathrm{cm}^{2}$ at $4.9 \mathrm{~V} / \mu \mathrm{m}$ on samples Co1 and Co2, respectively. Moreover, on sample Co1 one needs a long set of pretreatments before finding stable emission conditions. The emitting sites could be the long filaments merging above the dense forest of small Co@CNTs. These scarce long tubes are progressively burnt off in the course of the first cycles and the smaller value of $\beta$ then obtained stems for a high density of nanotubes of nearly the same length. The sample Co2 displays more interesting field emission properties with rather a high $\beta \geqslant 1500$. This difference compared to Co1 can be explained by the fact that the filamentous nanostructures, whose shape is about the same, are more regularly ordered above the CNTs forest, decreasing screening effects by vicinal nanotubes. The low threshold field around $2 \mathrm{~V} . \mu \mathrm{m}^{-1}$ is conjugated with a very stable emission. However a strong saturation is observed at a low value of $\sim 85 \mu \mathrm{A} / \mathrm{cm}^{2}$ and a low field around $5 \mathrm{~V} / \mu \mathrm{m}$.

\subsection{Field emission from carbon nanotubes with Co catalysts with different ammonia concentrations}

The samples Co3 and Co4 are grown at 0 and 16\% ammonia concentrations, respectively (Tab. 2). It has been shown elsewhere that the nature of the nanostructures is highly sensitive to the ammonia concentration [33]. Thus without ammonia within the gas phase, new carbon nanostructures can be grown, whereas at low ammonia concentration $\left(0.5<\mathrm{NH}_{3}<3 \%\right)$ CNTs are readily obtained. At larger $\mathrm{NH}_{3}$ concentrations, the etching of the surface overcomes the deposition of carbon, and 

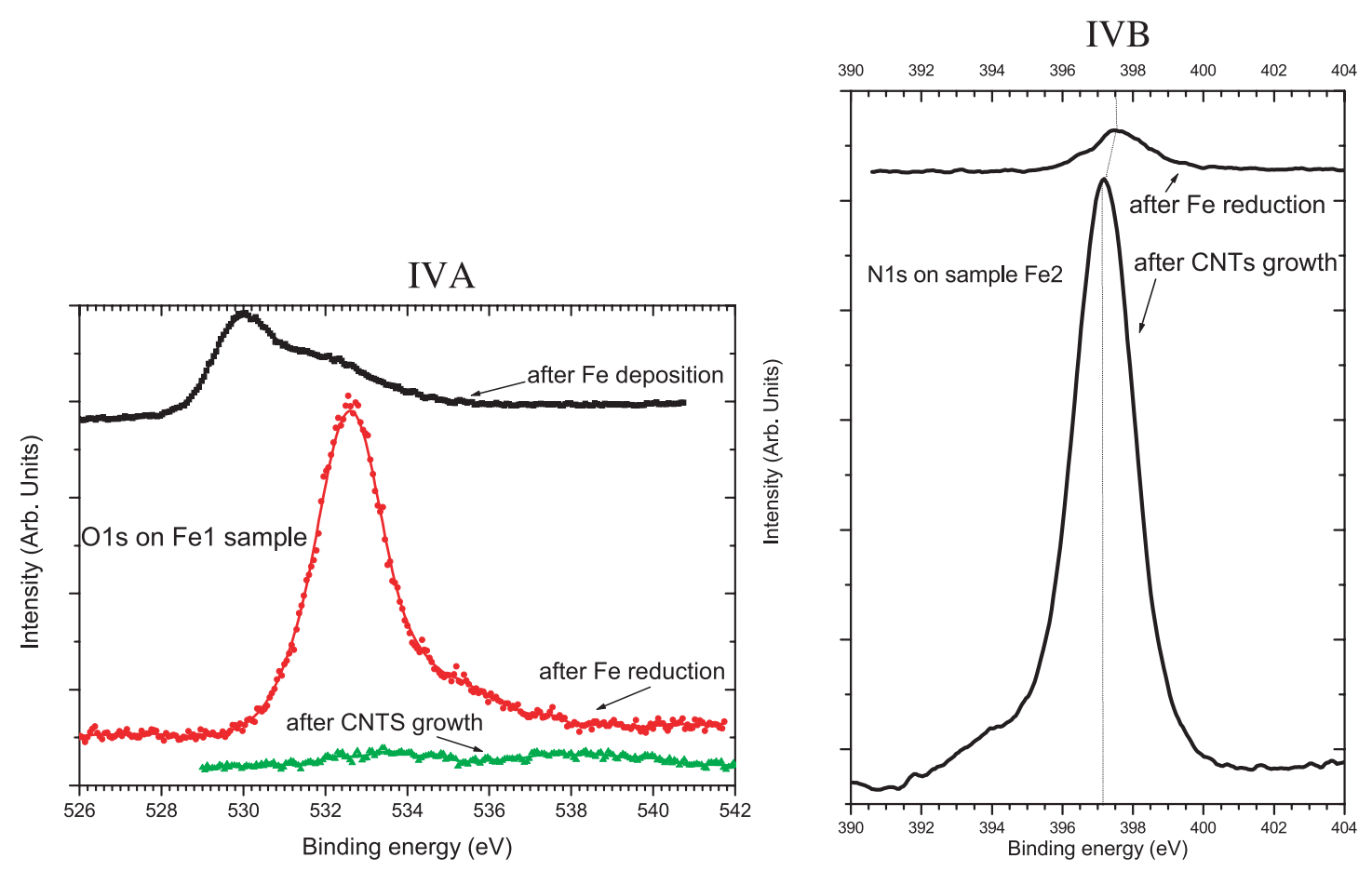

Fig. 4. Continued.

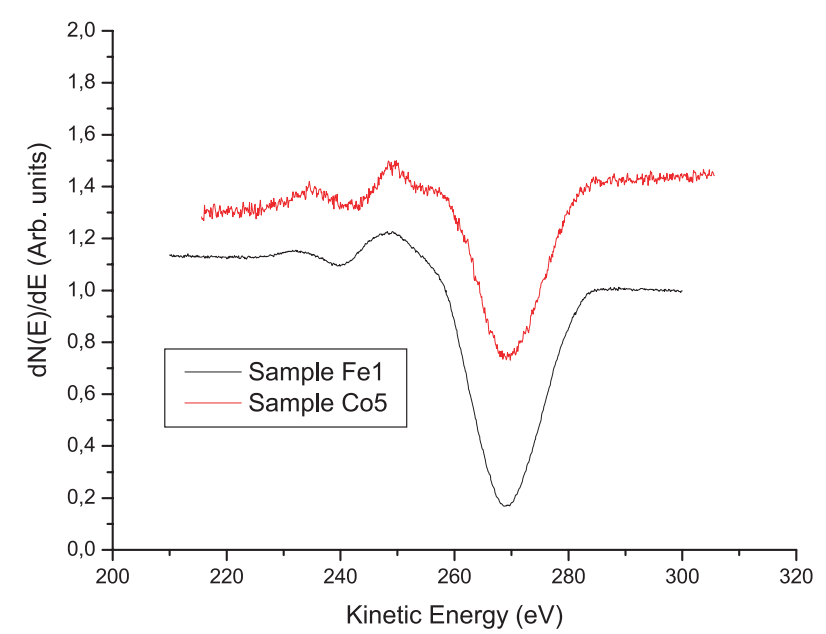

Fig. 5. AES on the C KVV level: Fe1 (full); Co5 (dotted).

silicon-based nanostructures are now grown. This is illustrated in Figures 2F, C, E and Figures 3F, E and G for samples Co4, Co1 and Co3 with ammonia concentrations $0 \%, 3 \%$ and $16 \%$, respectively. From the SEM and TEM images all the nanostructures exhibit high density and aligned morphology oriented along the direction normal to the substrate with a metallic particle on top of them. The nature of these nanostructures is however strongly different. On sample Co3 with $16 \%$ ammonia within the gas phase, the absence of any $\mathrm{C} 1 s$ signal in the XPS wide scan, as well as the absence of any carbon signal (D and G bands) in the Raman spectrum indicates that the chemical nature of the nanostructure is not made up of carbon. By contrast, intense N1s and Si2 $p$ single lines can be ev-

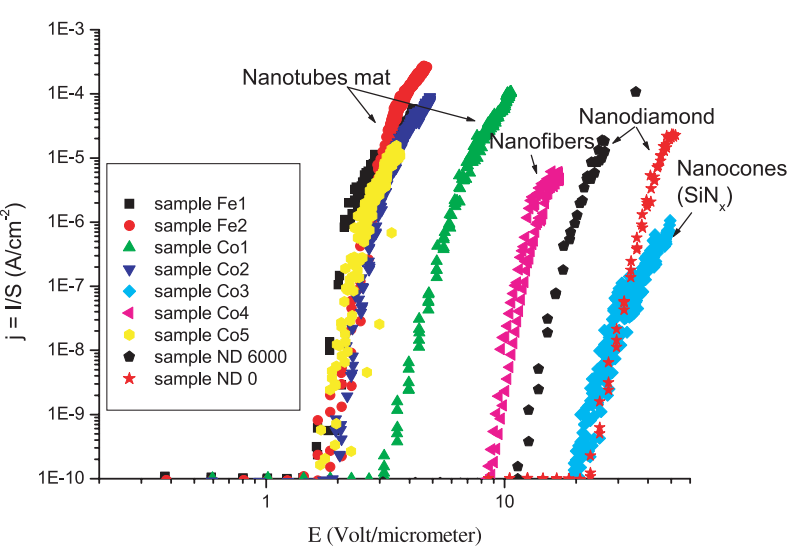

Fig. 6. $j=f(E)$ plots of the nanostructures prepared for a set of some stabilized cycles.

idenced with a $\mathrm{Si} / \mathrm{N}$ ratio around 0.8 (corrected for the photoionization cross sections), not far from the expected 0.75 one for the stoichiometric silicon nitride $\mathrm{Si}_{3} \mathrm{~N}_{4}$. Moreover the initial Si $2 p$ signal initially split into silicon and silicon oxide contributions coalesces after the CVD process into one single contribution around $101.5 \mathrm{eV}$ (Fig. 4-IIIB). From structural investigations it can be seen that these nanocones are mainly amorphous (Fig. 3E). It is therefore tempting to assimilate these nanostructures to amorphous silicon nitrides, possibly slightly oxidized. The distribution of these nanocones is quite homogeneous with a base diameter around $25 \mathrm{~nm}$ and a curvature radius around $10 \mathrm{~nm}$. On the other hand the XPS wide scan recorded on the Co4 sample, grown without ammonia within the gas mixture, exhibits now a noticeable $\mathrm{C} 1 s$ signal. In addition 


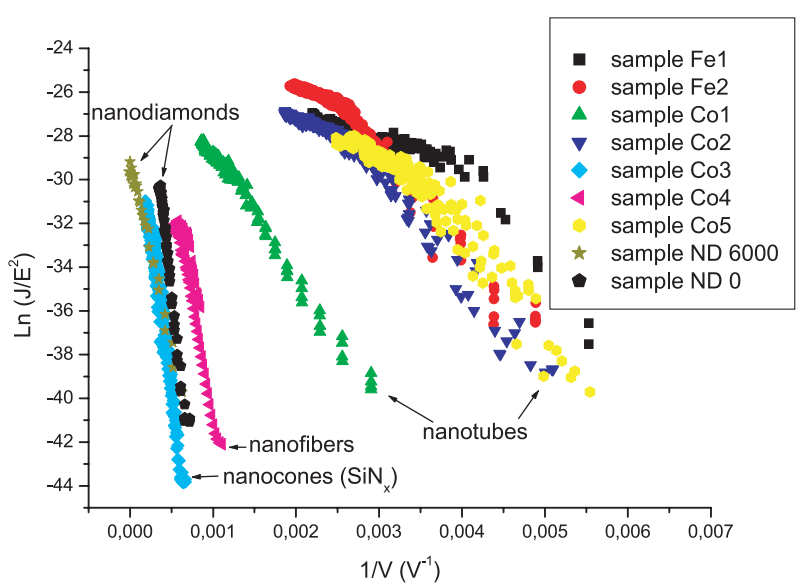

Fig. 7. FN-plots $\operatorname{Ln}\left(\mathrm{j} / \mathrm{E}^{2}\right)=\mathrm{f}(1 / \mathrm{V})$ of the nanostructures, for a set of some stabilized cycles.

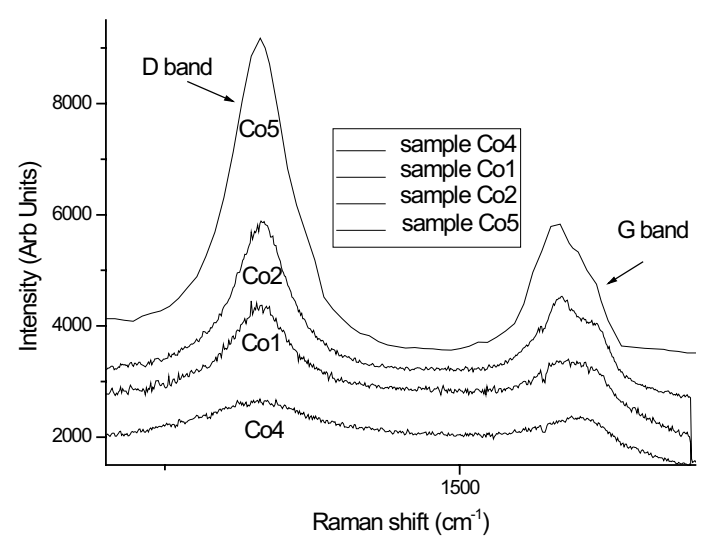

Fig. 8. Raman spectra.

the Raman spectrum exhibits two bands at $1328 \mathrm{~cm}^{-1}$ (D band) and $1585 \mathrm{~cm}^{-1}$ (G band). TEM examinations provide a clear picture of these nanostructures which are now entirely filled with carbon. The graphitic planes, distant by $0.34 \mathrm{~nm}$ each other, are oriented parallel to the substrate surface with a platelet morphology (Figs. 3F, G) and an isotropic cobalt particle is encapsulated on top of it (Figs. 2E, 3F, 3G). Finally the much broader Raman G and $\mathrm{D}$ bands also support a different structural arrangement of the carbon nanostructures (Fig. 8). In conclusion these nanostructures might be described more as carbon fibers (CFs) rather than carbon nanotubes. In the absence of ammonia the different morphology obtained for the carbon nanostructures, as well as the different morphology of the catalytic particles on top of it (isotropic instead of anisotropic), suggest that the nature of the plasma created is quite different and induced a different mechanism of growth [17].

These aligned nanostructures display an anisotropic morphology which is prone for electron field emission, albeit the conical shape observed in Co3 sample is far from the model shape of a whisker. Thus the assumption of $\beta$ to the aspect ratio (length/lateral diameter) of the nanocone is not yet strictly valid [41]. This can explain the sensible drop of this factor to around 200 as deduced from the linear FN behavior (Fig. 7). More important, the emission thresholds occur at much higher electric fields than the carbon nanotubes: $8.2 \mathrm{~V} / \mu \mathrm{m}$ for the platelet graphitic nanocones and $14.5 \mathrm{~V} / \mu \mathrm{m}$ for the silicon-based nanocones with many cycles in both cases before reaching reproducibility. Moreover saturation densities are rapidly reached. The emission densities at saturation decrease by more than one order of magnitude $\left(4.8 \mu \mathrm{A} / \mathrm{cm}^{2}\right.$ at $\left.17 \mathrm{~V} / \mu \mathrm{m}\right)$ on graphitic nanocones and by more than two orders of magnitude $\left(0.5 \mu \mathrm{A} / \mathrm{cm}^{2}\right.$ at $43 \mathrm{~V} / \mu \mathrm{m})$ on silicon-based nanocones, respectively. This can be easily understood in the case of silicon nanostructure whose electron conduction is not known but can be estimated to be low. In the case of the platelet graphitic morphology, the electron conduction occurs from an electron transport from one graphitic base plan to another one, instead of an electron transport inside curved basal shells in the case of carbon nanotubes. In the former case the very low electrical conductivity leads to a rapid saturation of the electron transport to the emitting surface site. Thus a conductivity ratio $\sigma_{a} / \sigma_{c} \approx 2300$ is reported for HOPG graphite [42] in the directions parallel and normal to the graphitic base plan, respectively.

\subsection{Field emission from carbon nanotubes with Co catalysts with different deposition techniques}

We have compared the field emission properties of Co samples in which Co particles are prepared through different deposition methods. In sample Co5, Co is in situ deposited by vacuum evaporation instead of magnetron sputtering on Co4 sample. Unlike carbon nanofibers on Co4 sample, CNTs are now grown with an uniform diameter around $15 \mathrm{~nm}$ (Fig. 2G and Fig. 3H). We have shown elsewhere that the nature of the carbon nanostructure may be strongly dependent on the mode of deposition of the catalytic layer deposition, especially through a different adhesion of the metallic particle to the substrate $[17,18]$. The C KVV Auger signal is displayed in Figure 5. It is not structureless and quite characteristic of carbon nanotubes. Field emission properties of the CNT films are similar to those above obtained with low emission threshold and high enhancement factor (Tab. 2).

\subsection{Field emission from diamond films doped with nitrogen}

The diamond films grown with 6000 ppm and without ammonia in the gas phase are shown in Figures 2I and 2H, respectively. The morphology of the diamond films exhibits major changes with addition of ammonia in the gas phase. Whereas the polycrystalline diamond film shows facetted grains with sizes smaller than $1 \mu \mathrm{m}$ and a general [111] growth orientation, the ND6000 sample exhibits quite rounded-shape grains of "cauliflower" morphology, indicating either nitrogen incorporation or many localized 


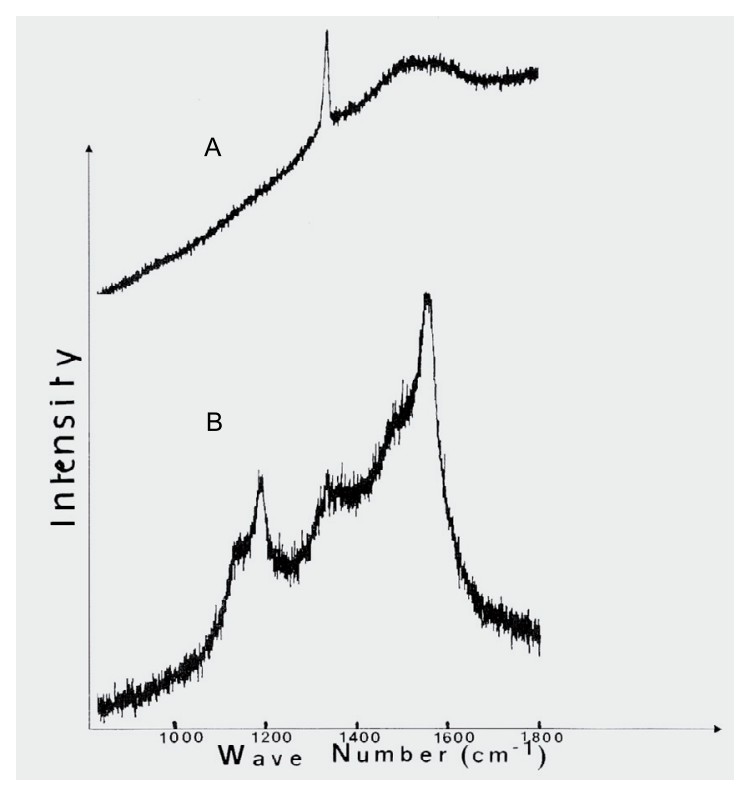

Fig. 9. Raman spectra on diamond films (A) ND0 and (B) ND600.

defects formation with graphitic carbon formation. Furthermore in situ XPS investigation (not shown) clearly indicates that a nitrogen signal is hardly evidenced. More details on the properties of the nitrogen-doped diamond films as a function of the ammonia content within the gas phase are reported elsewhere [43]. The Raman spectrum of the diamond films grown in the presence of ammonia also displays quite major modifications (Fig. 9). Whereas the diamond film ND0 exhibits the sharp D contribution at $1334 \mathrm{~cm}^{-1}$ corresponding to the $\mathrm{A} 1 \mathrm{~g}$ vibration mode and a broad and weak $\mathrm{G}$ band around $1560 \mathrm{~cm}^{-1}$ corresponding to the $\mathrm{E} 2 g$ vibration mode developing over a rising photoluminescence background, the spectrum on sample ND6000 exhibits many other bands while the D peak almost vanishes. Contributions at $1142 \mathrm{~cm}^{-1}, 1191 \mathrm{~cm}^{-1}$, $1510 \mathrm{~cm}^{-1}$ and $1555 \mathrm{~cm}^{-1}$ may be assigned to the presence of new carbon species (surface carbon, trans-acethylenic carbon, graphitic-like clusters, ... ). The discussion about these Raman spectra is presented in more details elsewhere [43]. The main conclusion from these studies of the properties of diamond films is that the morphology of the diamond films is deeply transformed through the introduction of ammonia into the gas phase. However this will not infer that stable nitrogen is deeply incorporated into the films but rather the nitrogen-containing gas species are more prone to create an intense concentration of lattice defects throughout the growth and to generate graphitic carbon species.

The field emission properties on diamond samples with different ammonia content in the gas phase in the range 0-10 $500 \mathrm{ppm}$ are summarized in Table 1. The threshold emission occurs at large electric field $(25 \mathrm{~V} / \mu \mathrm{m})$ with a low emission density, a rather good stability of the emission after many cycles. Reversely in the presence of ammonia the emission can start initially at a lower threshold down to $5 \mathrm{~V} / \mu \mathrm{m}$ for ND6000 sample, but this emission is never stable and the emission threshold rapidly increases to values equivalent to and even higher than those observed on ND0 sample.

\section{Discussion}

Thresholds for field emission are quite variable according to the sample but these variations are clearly dependent on the nature of the carbon material. Here carbon materials with different structural configurations (doped or undoped diamond, graphite), different crystalline states (amorphous or crystalline) and different morphologies (flat films, oriented films normal to the surface with graphite basal planes either parallel or normal to the surface) were prepared in the same experimental set up.

Thus for the CNT films, threshold fields are within the $1-4 \mathrm{~V} / \mu \mathrm{m}$ range, rather independent on the nature of the metal catalyst or the growth temperature. These values are in agreement with other data of the literature (in the order of some $\mathrm{V} / \mu \mathrm{m}$ for nanotubes), considering however that the definition of the emission threshold and the experimental set up might be different [1]. We do not find at this stage any significant effect of the transition metal as the difference observed between $\mathrm{Fe}$ and $\mathrm{Co}$ is within the experimental errors. The slightly larger emission threshold observed on sample Co1 might be explained from the Raman spectra (Fig. 8). From these spectra the intensity ratio of the $\mathrm{G}$ band to the $\mathrm{D}$ band $\left(I_{D} / I_{G}\right)$ is calculated to $0.37,0.60$ and 0.58 on samples Co1, Co2 and Co5, respectively. Thus the shift of the threshold towards larger fields can be explained by a higher density of defects in the nanotubes on sample Co1.

By contrast the threshold fields on the nanofibers and the nanocones, in the graphitic as well as in the siliconbased forms, are strongly shifted towards higher fields. This is accompanied with much lower enhancement factors $\beta$. As the densities and the mean size of the nanostructures are rather similar within one order of magnitude, it can be concluded that these difference can be due to a difference in the nature of these nanostructures. Another factor can be found in the insulator character of these nanostructures. This is obvious for the silicon nitride nanocones, but also for the carbon nanofibers. When the basal graphitic planes are oriented perpendicularly to the direction of the electron transport, it is expected that the electron conduction will be impeded. This conductivity also explains the saturation of the emission observed on all the samples with a deviation of the FowlerNordheim plot (Fig. 7). It must be recalled that, when ammonia is present within the gas phase, the $\mathrm{SiO}_{2}$ barrier is fully transformed into silicon nitride $\mathrm{SiN}_{x}$, probably as an amorphous phase (Fig. 4-IIIB). Thus the electron conduction occurs through channeling through an amorphous $\mathrm{SiO}_{2}$ or $\mathrm{SiN}_{x}$ layer. Despite the absence of conductivity data through these layers, it is no doubt that the nature, as well as the thickness or the rugosity, of these layers will influence the saturation of the electron emission at high fields. Generally it is observed that the emission density at saturation closely relates to the field enhancement 
factor (Tab. 2). However adhesion of the nanostructure may explain some discrepancy to this behavior. The very low saturation density on sample Co5, in spite of the low threshold emission, can be related to a poor adhesion of the nanostructure to the substrate via the formation of a nest of graphic planes parallel to the surface during the nucleation of the nanotube [17]. This mode of adhesion results from the mild deposition conditions of catalytic particles through thermal vacuum evaporation (MBE) used in the case of the Co5 sample, whereas by the sputtering process used for other $\mathrm{Co}$ and Fe samples stronger adhesion impedes the formation of such graphitic nest and improves the conductivity at the interface.

By contrast the field emission from diamond films nanostructures is expected to occur from less sharp nanostructures and this is partly checked by the much lower enhancement factors observed. However significant changes occur in the diamond films when $\mathrm{NH}_{3}$ is added within the gas phase for grain size and grain morphology, from facetted surfaces to cauliflower morphology due to secondary nucleation [44-46]. These changes cannot be explained only by some incorporation of nitrogen within the diamond films as from XPS investigations it has been shown that the nitrogen content remains vanishingly small. More probably morphological modifications and new graphitic carbon species are formed, as depicted by SEM (Fig. 2-I) and Raman spectra (Fig. 9).

Finally some non stabilized electron field emission occurs according to the cycles. The reasons of these variations must be found in a continuous process of consumption of the sites that leads to a different distribution of the sites from one cycle to another one. In addition it is possible that the high flexibility of numerous nanotubes leads to modifications of the distribution of the emitter sites. This is especially the case for thin nanotubes which are known to be highly flexible and some of them can orientate along the field lines. In the case of doped-diamond films a shift towards higher emission thresholds is systematically observed. One explanation could be a nitrogen removal from the samples as it is shown that the emission properties of the doped-ND samples after many cycles are similar to the emission properties of the stable undoped ND0 sample.

\section{Conclusion}

The electron field emission properties of different graphitic and diamond-like nanostructures films are compared. Films of dense and aligned carbon nanotubes by far display the lowest threshold fields around few $\mathrm{V} / \mu \mathrm{m}$ and the largest emission current density. Carbon nanofibers, with platelet arrangement of the graphitic planes parallel to the flat substrate, exhibit higher emission thresholds around $10 \mathrm{~V} / \mu \mathrm{m}$. Diamond nanostructures, either modified through ammonia incorporation within the gas phase or not, exhibit the largest emission threshold around $25 \mathrm{~V} / \mu \mathrm{m}$. The high enhancement factors, deduced from the Fowler-Nordheim plots, can explain the low emission thresholds whereas limitations to the electron transport ever occur through different processes (i) surface modifications of the surface, as the transformation of $\mathrm{SiO}_{2}$ barrier layer into $\mathrm{SiN}_{x}$ in the presence of ammonia as evidenced by XPS, (ii) different orientation of the graphitic basal planes relative to the direction of electron transport in carbon nanofibers and (iii) presence of a graphitic nest at the interface of the carbon nanostructure and the substrate, observed when catalyst is deposited through mild evaporation.

Anyway the density of CNTs or other nanostructures here obtained is by far too large to optimize the screening of the tubes. Therefore it is important to work with catalysts spread on a surface as an array and to work with conductive surface that are both a barrier to the diffusion and able to get and to stabilize small metallic particles at high temperatures. Much effort is performed on these issues.

J. Faerber, G. Ehret and G. Schmerber are acknowledged for SEM, TEM characterizations and film preparations, respectively.

\section{References}

1. J.M. Bonard, H. Kind, T. Stockli, L.-O. Nilsson, Solid State Electron. 45, 893 (2001)

2. M.J. Fransen, T.L. van Rooy, P. Kruit, Appl. Surf. Sci. 146, 312 (1999)

3. W.A. De Heer, J.M. Bonard, Z. Phys. D 40, 418 (1997)

4. J.M. Bonard, T. Stockli, F. Maier, W.A. de Heer, A. Chatelain, J.P. Salvetat, L. Forro, Phys. Rev. Lett. 81, 1441 (1998)

5. S.T. Purcell, P. Vincent, C. Journet, V.T. Binh, Phys. Rev. Lett. 88, 105502 (2002)

6. O. Groening, O.M. Kuttel, C. Emmenegger, P. Groening, L. Schlapbach, J. Vac. Sci. Technol. B 18, 665 (2000)

7. V.V. Zhirnov, O. Groning, O.M. Kuttel, A. Alimova, P.Y. Detkov, P.I. Belobrov, E. Maillard-Schaller, L. Schlapbach, J. Vac. Sci. Technol. B 17, 666, (1999)

8. A.N. Obraztsov, A.P. Volkov, I. Yu. Pavlovskii, E.V. Rakova, S.P. Nagovitsyn, J. Electrochem. Soc. 145, 2572 (1998)

9. A.N. Obraztsov, A.P. Volkov, I. Yu Pavlovskii, JETP Lett. 68, 59 (1998)

10. T.W. Ebbesen, in Carbon Nanotubes: Preparation and Properties, edited by T.W. Ebbesen (CRC Press, Boca Raton, 1997)

11. P.M. Ajayan, Chem. Rev. 99, 1787 (1999)

12. W. Zhu, C. Bower, O. Zhou, G. Kochanski, S. Jin, Appl. Phys. Lett. 75, 873 (1999)

13. V.V. Zhirnov, J.J. Hren, MRS Bull. 09, 42 (1998)

14. M.W. Geis, J.C. Twichell, T.M. Lyszczarz, J. Vac. Sci. Technol. B 14, 2060 (1996)

15. O. Groning, L.O. Nilsson, P. Groning, L. Schlapbach, Solid State Electron. 45, 929 (2001)

16. M. Larijani, C.S. Cojocaru, D.S. Misra, M.K. Singh, P. Veis, F. Le Normand, Diam. Relat. Mater. 13, 270 (2004)

17. C.S. Cojocaru, F. Le Normand, J. Nanosci. Nanotechnol. 6, 1 (2006)

18. C.S. Cojocaru, F. Le Normand, Thin Solid Films 515, 53 (2006) 
19. Y. Chen, Z.L. Wang, Y.S. Yin, D.J. Johnson, R.H. Prince, Chem. Phys. Lett. 272, 178 (1997)

20. Z.F. Ren, Z.P. Huang, J.W. Xu, J.H. Wang, P. Bush, M.P. Siegal, P.N. Provencio, Science 282, 1105 (1998)

21. Y. Chen, Y. Ye, L. Guo, S. Patel, D.T. Shaw, Appl. Phys. Lett. 73, 2119 (1998)

22. Z.P. Huang, J.W. Xu, Z.F. Ren, J.H. Wang, M.P. Siegal, P.N. Provencio, Appl. Phys. Lett. 73, 3845 (1998)

23. Y. Chen, L. Guo, S. Patel, D.T. Shaw, J. Mater. Sci. 35, $5517(2000)$

24. J.H. Han, W.S. Yang, J.B. Yoo, C.Y. Park, Surf. Coat. Tech. 131, 93 (2000)

25. J.H. Han, W.S. Yang, J.B. Yoo, C.Y. Park, J. Appl. Phys. 88, $7363(2000)$

26. Y. Hayashi, T. Negishi, S. Nishino, J. Vac. Sci. Technol. A 19, 1796 (2001)

27. Z.P. Huang, J.G. Wen, M. Sennett, H. Gibson, Z.F. Ren, D.Z. Wang, Appl. Phys. A 74, 387 (2002)

28. Ch. Taschner, F. Pacal, A. Leonhardt, P. Spatenka, K. Bartsch, A. Graff, R. Kaltofen, Surf. Coat. Tech. 174, 81 (2003)

29. B.A. Cruden, M. Meyyappan, Q. Ye, A. Cassell, J. Appl. Phys. 94, 4070 (2003)

30. Y. Shimizu, T. Sasaki, T. Kodaira, K. Kawaguchi, K. Terashima, N. Koshizaki, Diam. Relat. Mater. 14, 11 (2005)

31. J.H. Han, H.J. Kim, C.W. Yang, W.S. Yang, Y.H. Song, K.S. Nam, J.B. Yoo, C.Y. Park, Mat. Sci. Eng. C 16, 65 (2001)

32. C.S. Cojocaru, D. Kim, D. Pribat, J.E. Bouree, Thin Solid Films 501, 227 (2006)
33. B. Vigolo, C.S. Cojocaru, J. Faerber, J. Arabski, F. Le Normand, J. Nanosci. Nanotechnol., to be published

34. J.C. Arnault, L. Demuynck, C. Speisser, F. Le Normand, Eur. J. Phys. Chem. B 11, 327 (1999)

35. G. Pirio, P. Legagneux, D. Pribat, K.B.K. Teo, M. Chhowalla, G.A.J. Amaratunga, W.I. Milne, Nanotechnology 13, 1 (2002)

36. J.M. Bonard, in Understanding carbon nanotubes. From basics to application, edited by A. Loiseau et al. (Springer, Berlin 2006)

37. M. Brodie, J. Spindt, J. Appl. Phys. 47, 5248 (1976)

38. J. Mulder, in Handbook of X-ray photoelectron spectroscopy (Perkin Elmer, 1982), p. 147

39. Y. Wei, C. Xie, K.A. Dean, B.F. Coll, Appl. Phys. Lett. 79, 4527 (2001)

40. Z.L. Wang, R.P. Gao, W.A. De Heer, P. Poncharal, Appl. Phys. Lett. 80, 856 (2002)

41. T. Utsumi, IEEE T. Electron Dev. 38, 2276 (1991)

42. P. Bernier, S. Lefrant, Le carbone dans tous ses états (Gordon and Breach Science Publ., Amsterdam, 1997), p. 24

43. Z.Q. Li, M. Gulas, B. Prevot, C.S. Cojocaru, F. Le Normand (in preparation)

44. S. Jin, T.D. Moustakas, Appl. Phys. Lett. 65, 403 (1994)

45. R. Locher, C. Wild, N. Herres, D. Behr, P. Koidl, Appl. Phys. Lett. 65, 34 (1994)

46. G.Z. Cao, J.J. Schermer, W.J.P. Van Enckevort, W.A.L.M. Elst, L.J. Giling, J. Appl. Phys. 79, 1357 (1996)

To access this journal online: www.edpsciences.org 